on defining and recognising psychological problems and outlines the main approaches to treatment. There are sections on different models of liaison psychiatry services and how to arrange for their purchase (liaison psychiatry is the subspecialty of psychiatry concerned with clinical service, teaching, and research in non-psychiatric health care settings). ${ }^{13}$

Training for specialists and non-specialists has a separate section, although there is unfortunately nothing on the relevance of liaison psychiatry to undergraduate education. The refocusing of undergraduate medical education by the General Medical Council ${ }^{14}$ has highlighted the need for training in those aspects of psychiatric practice required most urgently by newly qualified house staff, and most of these are recognisably within the remit of the working group's report.

There is a welcome guide for purchasers, many of whom will not think about these issues unless carefully briefed to do so. The advice is forthright: acute services in general hospitals should be purchased only where an adequate liaison service is included, and the cost of the liaison psychiatry service should be included within the costs of each medical service. Quality of service and expediency are among the reasons for arranging integrated physical and psychiatric care. There is also a financial argument. One study from the United States showed that an orthopaedic liaison psychiatry service paid for itself by reducing lengths of stay by an average of two days, saving more than $\$ 250000$ of the inpatient costs of treating 452 patients. ${ }^{15}$

For those who want the planning of services to be evidence based, the authors have included an extensive bibliography to support their conclusions and recommendations. This important report deserves to be widely read and acted on by those who commission care for physically ill patients and those who provide it.

ALLAN HOUSE

Department of Liaison Psychiatry, Consultant and senior lecturer

Leeds General Infirmary,

Leeds LS1 3EX

MICHAEL FARTHING Professor

Digestive Diseases Research Centre,

Medical College of St Bartholomew's Hospital, London EC1M 6BQ

Department of Psychiatry,

Royal South Hants Hospital

Southampton SO14 OYG

Moffic HS, Paykel ES. Depression in medical in-patients. Br $f$ Psychiatry 1975;126:346-53.

2 Rodin G, Voshart K. Depression in the medically ill: an overview. Am $\mathcal{f}$ Psychiatry 1986;143: 696-705.

Mayou R, Hawton K. Psychiatric disorder in the general hospital. Br f Psychiatry 1986;149:172-90.

4 Johnston M, Wakeling A, Graham N, Stokes F. Cognitive impairment, emotional disorder, and length of stay of elderly patients in a district general hospital. Brf Med Psychol 1987;60:133-9.

5 Thomas R, Cameron D, Fahs M. A prospective study of delirium and prolonged hospital stay. Arch Gen Psychiatry 1988;45:937-40.

6 Jones $\mathrm{K}$, Vischi TR. Impact of alcohol, drug abuse and mental health treatment on medical care utilisation. Medical Care 1979;17(suppl):1-82.

7 Lloyd G, Chick J, Crombie E. Screening for problem drinkers among medical inpatients. Drug Alcohol Depend 1982;10:335-59.

8 Bass C, ed. Somatization: physical symptoms and psychological illness. London: Blackwell, 1990

9 Creed F, Mayou R, Hopkins A, eds. Medical symptoms not explained by organic disease. London: Royal College of Psychiatrists and Royal College of Physicians of London, 1992.

10 Saravay S, Lavin M. Psychiatric comorbidity and length of stay in the general hospital: a critical review of outcome studies. Psychosomatics 1994;35:233-52.

11 House A. Psychiatric disorders, inappropriate health service utilization and the role of consultation liaison psychiatry. $\mathcal{F}$ Psychosom Res (in press).

12 Royal Colleges of Physicians and Psychiatrists. foint working party report: the psychological care of medical patients: recognition of need and service provision. London: RCGP, 1995.

13 Benjamin S, House A, Jenkins P. Liaison psychiatry - defining needs and planning services. London Gaskell Press, 1993.

14 General Medical Council. Tomorrow's doctors. Recommendations on undergraduate medical training. London: GMC, 1993.

15 Strain J, Lyons JS, Hammer J, Fahs M, Lebovits A, Paddison P, et al. Cost offset from a psychiatric consultation-liaison intervention with elderly hip fracture patients. Am f Psychiatry 1991;148: $1044-9$.

\title{
Human tissue: ethical and legal issues
}

\section{The report from the Nuffield Council on Bioethics provides a coherent legal and ethical approach}

Advances in biotechnology and increasing public concern about the uses to which human tissue may, can, or should be put make the recent report of the Nuffield Council on Bioethics timely and important. ${ }^{1}$ It provides a lucid, rigorous, and balanced view of the dilemmas that the potential scientific uses of human tissue pose for ethics and the law. The report is wide in its approach, dealing with everything from physical and intellectual property rights to confidentiality, compensation, and capacity.

In its coverage of ethics the report takes an imaginative, although not unarguable, approach which effectively eschews strict adherence to more traditional approaches (such as utilitarianism), concentrating instead on two fundamental principles - the avoidance and limitation of injury and (a secondary consideration) matters of consent. This approach seeks to provide a form of practical ethics that the more standard theories have, in the view of the working party, failed to achieve. The working party therefore starts from a permissive rather than an inherently restrictive perspective, seeking harmony and balance rather than to choose one ideology over another. Even though argument with this perspective is possible, it provides an unusually cohesive basis from which to stimulate debate, and if for no other reason than this it is to be welcomed.

One of the report's most important conclusions is that the intention behind the use of human tissue should play an important part in the ethics and lawfulness of this use. Although avoiding and limiting injury is regarded as a "basic requirement," much of the report necessarily concerns two other concepts-consent and property. In the discussion of consent special attention is paid to children and to people who are legally incompetent. Unfortunately, the sections concerning children refer exclusively to the position in English law (which may have important differences from Scottish law), and certainly the conclusions drawn are not necessarily applicable to those beyond the jurisdiction of English common law and courts. However, the principles that emerge-that children should be encouraged to participate in decision making, that any sign of refusal should be taken seriously, and that parents (or equivalent) should be deemed capable of consenting as proxies-are protective of the interests at stake, even if the lawfulness of proxy consent by parents is controversial.

With respect to mentally incapacitated adults the report notes that consent is effectively unobtainable in current law. None the less, pragmatic ethics might suggest that a way round this should be found, and this, the report suggests, might be achieved by invoking the public interest, always provided that the basic ethical principle of avoiding harm is borne in mind and that the uses to which the tissue is to be put are ethical. This would give mentally incapacitated people protection equivalent to that enjoyed by children 
and would permit some uses that otherwise seem to be prohibited.

Significantly, in the debate over property rights in human bodies or parts thereof the conclusion is that there may be some property rights in human body parts but that, as with all such rights, constraints will nevertheless exist on how such rights can be exercised and the uses to which human tissue can be put. Property, in addition, might be a useful concept, but not to the extent that it involves commercialism. In an effort to clarify the legal status of body parts the report proposes that two presumptions should be taken as standard: firstly, that tissue removed in the course of treatment should be presumed to have been abandoned and, secondly, that if tissue is removed in other circumstances and donated voluntarily it may also be used if consent to the intended use is given. If adopted, these proposals would simplify what is otherwise an extremely complex question.
The report recognises the role of property rights in this arena but also highlights the uncertainties generated by the definition of what can be patented.

If the report's recommendations are taken seriously and those that are arguable are clarified then it could form the basis of a coherent legal and ethical approach. Ultimately, legislation may be necessary to provide the certainty that the report seeks, and the report recognises this. But even without legislation the report goes a long way towards resolving some of the difficulties posed by scientific activity in this field.

SHEILA MCLEAN

International Bar Association professor of law and ethics in medicine

School of Law,

University of Glasgow,

Glasgow G12 8QQ

1 Nuffield Council on Bioethics. Human tissue: ethical and legal issues. London: NCB, 1995.

\section{Poor response to erythropoietin}

\section{Should be fully investigated and treated}

Recombinant human erythropoietin was licensed for the treatment of renal anaemia five years ago, and over $90 \%$ of patients respond to it. ${ }^{1}$ But the few who do not are important both in clinical and financial terms: a $70 \mathrm{~kg}$ man failing to respond to a dose of $200 \mathrm{U} / \mathrm{kg} /$ week currently costs the NHS $£ 6500$ a year.

The definition of a poor response to erythropoietin is arbitrary. As most patients with renal anaemia respond to 75-150 U/kg/week any such patient showing a rise in haemoglobin concentration of less than $10 \mathrm{~g} / 1 /$ month despite a dose of greater than $200 \mathrm{U} / \mathrm{kg} /$ week may be classed as a "poor responder." Several factors may be responsible: important causes include iron deficiency, ${ }^{23}$ blood loss, ${ }^{4}$ infection, and inflammatory conditions, including malignancy. ${ }^{56}$ Other causes include hyperparathyroidism with marrow fibrosis, ${ }^{7}$ aluminium toxicity, ${ }^{8}$ vitamin B-12 or folate deficiency, ${ }^{9}$ haemolysis, ${ }^{10}$ marrow dysfunction, ${ }^{11}$ red cell enzyme defects, and haemoglobinopathies. ${ }^{12} 13$

How do these conditions impair the response to erythropoietin? In some the pathogenesis is obvious-for example, absolute iron deficiency results in resistance to erythropoietin because iron is essential for synthesis of haem. But normal or even increased iron stores (as judged by the serum ferritin concentration) do not exclude the development of functional iron deficiency, in which iron stores are ample but there is a failure of supply of iron to the marrow or its use in erythropoiesis. ${ }^{3}$ Functional iron deficiency is the commonest cause of resistance to erythropoietin and is probably underdiagnosed, mainly because reliable markers for its detection are lacking. The serum ferritin concentration gives a reasonable indication of iron stores but may be spuriously raised in inflammatory conditions, infection, and liver disease. ${ }^{3}$ In theory, the transferrin saturation is a better indicator of how much iron is available to the marrow for erythropoiesis as it reflects the circulating amount of iron in the plasma relative to the total iron binding capacity. Although previous studies suggested that when the transferrin saturation falls below $16-20 \%$ iron supply for erythropoiesis is inadequate, this measurement is subject to considerable diurnal variation. ${ }^{3}$

Other indicators of functional iron deficiency in patients receiving erythropoietin include the proportion of hypochromic red cells in the circulation ${ }^{14}$ and concentrations of red cell ferritin, red cell zinc protoporphyrin, free erythrocyte protoporphyrin, and serum transferrin receptor. ${ }^{315}$ Of these, the proportion of hypochromic red cells in the circulation-an indirect measure of how well iron is supplied to red cells for incorporation into haemoglobin - is probably the most useful and practical as it is easily performed with an autoanalyser.

The mechanisms by which blood loss, ${ }^{4}$ haemolysis, ${ }^{10}$ and vitamin B-12 and folate deficiency ${ }^{9}$ cause resistance to erythropoietin are obvious, as is their diagnosis and management. Treatment with erythropoietin is not very effective in conditions causing chronic marrow dysfunction ${ }^{11}$ such as myelodysplastic syndrome or sideroblastic anaemia, and it cannot correct genetic defects in haemoglobin synthesis in diseases such as sickle cell anaemia ${ }^{13}$ and thalassaemia. ${ }^{12}$

Whether hyperparathyroidism on its own causes resistance to erythropoietin is debatable; most evidence suggests that osteitis fibrosa must also be present. ${ }^{7}$ Aluminium toxicity causes a microcytic anaemia that is resistant to erythropoietin, probably by interfering with the transport and use of iron. ${ }^{8}$ The mechanisms by which infection, ${ }^{56}$ inflammatory disease, and malignancy ${ }^{6}$ impair responsiveness to erythropoietin are poorly understood. As in the anaemia of chronic disease, two mechanisms may be involved. Firstly, there is impaired availability and use of iron, ${ }^{16}$ and, secondly, erythropoiesis is suppressed by humoral factors, possibly other cytokines or growth factors. ${ }^{17}$ Many such factors have been implicated, but the two with the strongest support are tumour necrosis factor- $\alpha$ and interferon- $\gamma .{ }^{17}$

So much for the theory; how should we manage the poor responder? On the assumption that the patient is receiving at least $200 \mathrm{U} / \mathrm{kg} /$ week, the first step is to check the patient's compliance (if he or she is self injecting) and then assess his or her iron status. If the serum ferritin concentration is less than $100 \mu \mathrm{g} /$, the transferrin saturation is less than $20 \%$, or the proportion of hypochromic red cells is greater than $10 \%$ then iron deficiency may be present. If any doubt exists then a trial of intravenous iron supplementation is indicated. ${ }^{3}$ If iron deficiency has been excluded and there is no obvious cause of resistance to erythropoietin then several investigations should be done. These include measurement of reticulocyte count; analysis of a blood film; measurement of $C$ reactive protein concentration; testing for faecal occult blood; measurement 